\title{
Teacher-Researchers as Levers of Doctoral Curriculum in Engineering
}

\author{
https://doi.org/10.3991/ijep.v7i2.6765 \\ Pia Lappalainen \\ Aalto University, Language Centre \\ Leipzig University, Language Centre \\ pia.lappalaineneaalto.fi
}

\begin{abstract}
Policy-level interventions aim to expedite institutional change in universities but the related decisions rarely materialize as sustained grassrootslevel implementations genuinely transforming teaching or learning practices. As a solution, educational authorities have called for scientific evidence as base for university reforms. This article showcases an empirical development endeavor from Aalto University that, while responding to doctoral students' learning needs and institutional demands for higher publication productivity, paves the way for a more extensive bottom-up institutional reform of doctoral education. The data-driven analysis of a sample of 381 doctoral candidates in engineering directs the pedagogic focus in a doctoral writing course away from grammar and language proficiency towards writing support that accentuates usability and communicative value. The primary aim is to conceptualize a writing intervention that is based on authentic researcher needs. The secondary aim is to substantiate allocation of language teachers' working hours to research by demonstrating how audience needs analyses can benefit teacher renewal, the quality of education, and institutional performance as measured through key institutional metrics.
\end{abstract}

Keywords-doctoral education, language studies, publication productivity, student needs analysis

\section{Introduction}

In the competitive education economy, European universities are preoccupied with efforts to climb up the international ranking ladders to secure their reputation, to attract the most potent student material [1], to collect the largest possible share of state funding, and in the long run, to survive the global battle [2].

One of the fiercest rivalries materializes in the arena of doctoral education, in which productivity constitutes the traditional measure of institutional and individual performance. The expanding authorship community has produced a burgeoning number of publications, which compete for the citations of the simultaneously enlarging readership [3]. Citation counts and the related bibliometrics have been adopted to gauge the global reach and disciplinary status of university-hosted research [4] when 
substantiating tenure and funding decisions [5]. Productivity measures drive university performance also externally; as public funding is strongly dependent on performance indicators, universities are desperately seeking interventions increasing accountability by expediting doctoral degree completion and promoting a higher quality of candidate outputs [6], [7].

Even though the prevalent university improvement measures are, no doubt, well intended, they represent policy-level actions inspired by institutional pressure and are too rarely founded on research data on actual student needs or knowledge gaps. Politically motivated action typically pursues change for change's sake, seeking immediate gains at the cost of a more profound and sustainable reform [8]; [9] potentially even jeopardizing the university culture [10].

Subsequent calls for a university education reform, reconceptualization, reenvisioning, reframing, rethinking, harmonizing or formalizing are being voiced on European, national and university levels to address both the entrenched problems as well as some more recently articulated ones [11]. The former include such measurable outcomes as low and long completion times and graduates' poor match with industrial employment criteria, that is soft, intercultural [12], emotional, and social skills [13]. In contrast, the latter, more recently emerging issues center on higher-level goals, including the ability to tackle societal, social, economic, political, market and environmental challenges [14], [15].

Given the ramifications of publishing activity for the survival of individual universities, the small number of investments made in researchers' writing education comes as a surprise. Studies have shown that researchers universally need support in academic writing for publication [16] with their supervision typically being directed narrowly to the subject area and methodology.

As an effort to remedy this problem of practice, this article documents a grassrootslevel teacher-initiated analysis of students needs to show how syllabi can be reexamined and iteratively enhanced with reasonable efforts, adopting design-based research. The study subsequently offers two contributions to engineering pedagogy. First, it conceptualizes an intervention based on doctoral candidates' authentic learning needs. Second, it promotes a sustained and targeted bottom-up reform by appealing to Language Centre policy-makers to root a system allowing research investments in language teachers' annual contracts.

\section{Towards bottom-up university reform}

Such higher-level policy ideals instigated on the EU level as the Bologna Process aim to systematize higher education and accreditation criteria on the European level [17]. However, they may ignore the day-to-day realities of doctoral supervision as well as the requirements for supervisory care and ethics in the collaboration between the supervisor and the supervisee [18], which is known to affect the success of doctoral education [19].

Indeed, reports on successful university improvement endeavors have shown that internally generated changes typically yield the most positive impact compared to 
political imperatives. Naturally, traditional and taken-for-granted pedagogical practices offer value through automated, familiar routines [20] but have not proven effective in actualizing a positive change in degree attainment or in increasing the number of publications produced.

Another challenge induced by a change imposed top down is that it often envisions a desired goal but could fail to detail implementation. Without accurate diagnosis of the flaws, it is difficult to devise an improvement plan that allows transforming the change agenda from rhetoric attempts at renewal to a sustained reality. A vision without execution remains mere rhetoric or could even disrupt the persistent long-term development that committed teachers pursue as their more subtle and routine mode of operation [21].

A third hurdle in university development stems from contextuality, which hurdles effective replicability [22]. The local, institutional, professional, and classroom cultures and social make-up drive educational outcomes, questioning the benefits from replicating best practices from other countries, institutions or pedagogues [23]. Especially in doctoral education, borrowing previous reform strategies is an unfeasible option as systematic programs have only recently been set up, with little documented evidence of their success available thus far.

When genuinely pursuing change implementation, it is essential to keep in mind that despite the ostensible focus on the system level, the execution takes place in the classroom, through the teaching and learning processes. In the classroom, it is the teacher and his or her practices that contribute to student achievement; pedagogical leaders mediate learning outcomes by enacting an educational climate that either promotes or inhibits learning. The pedagogue's critical role in eliciting results among learners evokes performance beyond that explained by tangible resources [24], [25]. Profound instructional development therefore requires an internally motivated cultural change, which cannot be mandated. To authentically be able to act differently, teachers need self-renewal through capacity building that enhances their motivation, increments competences and secures resources [26].

Teacher capacity in doctoral programs refers centrally to the intellectual capital of the pedagogue [27], materializing as analytical and effective pedagogy. The focus in teaching activities, however, ought to be directed to service, which is in deliberate contrast to earlier approaches to doctoral education as top-down supervision. Serviceorientation also attends to the recent international shift toward the social nature of the supervisor-researcher relationship [28].

Supervision as service constitutes the centerpiece of the present study, which aims to expand understanding of the under-researched dimension of higher education that examines students as consumers [29], [30]. Traditionally, responsiveness to student needs has been pursued through supply-driven education based on pedagogues' prior understanding of student needs and the extensive insight into pedagogic development nationally cumulated in Finland. The Finnish teacher education system is globally recognized for its high quality, with teachers standing in high international esteem for their pedagogic expertise and top-notch PISA results [31]. Unfortunately, the Finnish pedagogical training essentially prepares teachers for the first two tiers in the education system, offering few instruments for the third, post-graduate level. 
The present calls to advance research on service-minded education pedagogy, particularly its breadth and diversity, as well as the personal relationships involved, strive to horizontalize the pedagogical space and the entire conception of doctoral education [32]. As a new conceptual dimension, students as consumers requires more targeted utility, high quality, factors ensuring personal interest, and individualized and unique study plans securing retention and study progress [33]. Doctoral candidates also expect practical relevance of their studies, preferably through integration of industrial operators into doctoral education [34], [35].

Unfortunately, the traditional language teacher role in Europe has not allowed research as part of the annual work contract, which would be instrumental also for teachers' occupational development and self-growth and professional renewal. The design-based research orientation is proposed here as a way of expanding the role of the language teacher into teacher-researcher. Further, this article examines systemslevel institutional change through an individual teacher's research efforts and describes a development initiative from Aalto University that is based on student needs. The results demonstrate that doctoral candidates require support not only in their core research activities, but also in tackling the various mental barriers and inhibitions related to documenting one's research. This study was motivated by calls to meet doctoral student needs more holistically and in a more targeted fashion but additionally ended up addressing the central tenets of teacher position in the university system. Ultimately, it aimed to enhance the quality of doctoral education and promote systemlevel change at Aalto University.

\section{Designing demand-driven doctoral education}

Following the basic-degree studies that are well formalized, structured and instructed, the ambiguous nature of doctoral studies easily discourages doctoral candidates, as does also the fierce competition. Scholarly publishing is depicted as communicative practice, with two competing aims: on the one hand, researchers are striving to have their products read and acknowledged by an audience as wide as possible; on the other hand, they must accommodate to the conventions of their own community in order to pass peer reviews [36].

These circumstances call for particular pedagogic approaches and modes of instruction. To design a doctoral course assisting doctoral candidates in the competitive, global research community, an investigation of doctoral candidates' needs was initiated by one of the English lecturers. The aim was to make student voices better heard and to consider their learning gaps more holistically in the curriculum design process. At the same time, the endeavor aimed to respond to the University management calls for faster doctoral degree completion and higher dissertation quality.

\subsection{Design-based research as the study method}

To build a pedagogically and scientifically informed education offering that meets student needs, the present study adopted a method following the principles of design- 
based research, as outlined in Figure 1. The method is well-established in learning sciences and serves both pragmatic and theoretical aims. It allows interventionist syllabus design that promotes a new type of a learning environment. The method enables an in-depth understanding of the learning process, as well as expansion of the teacher role into teacher-researchers [37].

The design-based research approach was adopted in the present examination to monitor doctoral candidates' perceptions in 2011-2016 through four, complementary rounds of analyses to identify topics, content and emphases for the new the Writing Doctoral Research course that was being set up for post-graduate students at the University Language Centre. Design-based research blends empirical educational research with the theory-driven design of learning environments and allows iterative, continuous cycles of implementation that move from design to enactment, analysis and redesign of pedagogical innovations. As outcomes, the method yields sharable theories that explain how the resultant designs function in authentic settings [38].

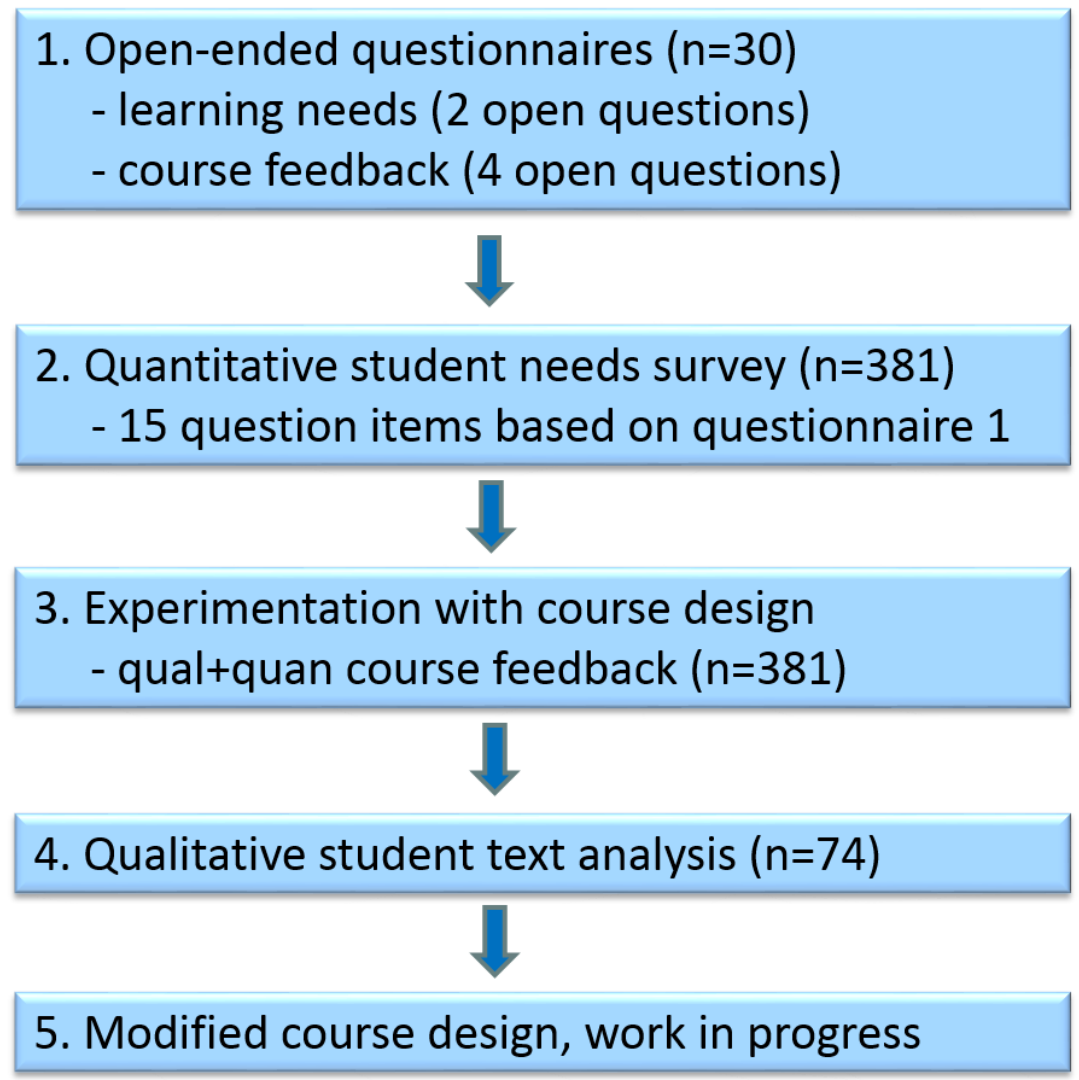

Fig. 1. Process of data collection. 
The first survey revealed some problems that could not be addressed by the Language Centre: too few lab facilities, poor lab maintenance, lack of professor-level supervision, missing support with methodological choices, and lacking or too shortterm funding instruments, which forces candidates to constantly engage in grant application. These messages were delivered to the University-level doctoral program management for further processing.

Leaving aside topics outside the Language Centre's authority, three main categories surfaced from the responses that dominated student perceptions in the two firststage questionnaires: content creation, production of text, and feedback reception. This is in alignment with prior literature indicating that writing for publication involves investment in content, process and critique [39]. Content refers to the ability to argue on the grounds of literature or empirical evidence. Process acknowledges scholarly writing as an iterative effort of rewriting. Finally, critique comprises skills in feedback reception and provision during the drafting and rewriting phases.

In the second phase, the three topic areas raised in the first two questionnaires were further divided into 15 sub-dimensions for a quantitative survey according to the key words in the student responses. They were organized into a survey using a Likert scale from 1 (not very important) to 5 (very important). Following the principles of design-based research and its cycle-based iterative development, every Writing Doctoral Research course begins with this survey, providing the teacher with valuable background information regarding the student audience. The accumulated responses presently comprise 381 respondents.

The qualitative analysis of 74 student abstracts or introductions was an important complementary method to acquire a more objective view of competence gaps, in addition to the subjective student views collected quantitatively. The analysis confirmed the results from the quantitative survey, corroborating that the utility of research writing education at Aalto needs to be enhanced and quality of publications improved with accentuated support for certain components in the writing process. The scrutiny revealed the need to specialize in engineering conventions specifically in quantitative methodology, and to direct attention to engineering socialization, theoretical profiling and enculturation [40] to accommodate to journal requirements. The analysis also revealed dimensions that students were unaware of: textual redundancy, inability to articulate thesis aims, ambiguous use of tenses and voices in data commentary, lack of hedging strategies, and overuse of passive constructions.

\subsection{Results - priorities for course design}

The scores received from the sample of 381 doctoral candidates were analysed for averages, medians and standard deviations to identify priorities for further course design (Table 1). The averages show that issues related to feedback were found to be of minor challenge among the 15 components but the mere fact that they were raised in student responses naturally calls attention to the emotive processes involved in critique. 
Table 1. Results from the quantitative survey $(n=381)$.

\begin{tabular}{|rlccc|}
\hline & & & & \\
& Question item & 3.76 & 1.03 & 3 \\
1 & Detecting my own mistakes & 3.69 & 0.89 & 3 \\
2 & Polishing my style & 3.63 & 0.90 & 3 \\
3 & Expressing my views with precision & 3.38 & 1.03 & 3 \\
4 & Mastering grammar & 3.36 & 0.92 & 3 \\
5 & Getting started with writing & 3.32 & 0.89 & 4 \\
6 & Arguing for my ideas & 3.27 & 0.89 & 4 \\
7 & Organizing sentences & 3.27 & 0.99 & 3 \\
8 & Deciding what to implement & 3.24 & 0.91 & 3 \\
9 & Organizing ideas & 3.23 & 0.98 & 3 \\
10 & Finding appropriate terminology & 3.04 & 0.80 & 4 \\
11 & Finding credible sources & 2.83 & 0.84 & 3 \\
12 & Generating ideas & 2.73 & 0.98 & 2 \\
13 & Understanding counter-arguments & 2.73 & 1.05 & 3 \\
14 & Not getting too emotional & 2.52 & 0.85 & 3 \\
\hline 15 & Accepting constructive criticism & & & \\
\hline
\end{tabular}

In the entire listing, two items, Getting started with writing and Not getting too emotional when receiving feedback yielded an above-average standard deviation, 1.01 and 1.06, respectively, indicating that some students deviated strongly from the general trend with their opposing perceptions. Three items received upper-scale medians: Detecting my own mistakes, Polishing my style and Expressing my views with precision, meaning that they were by half of the respondents scored as 5 in the survey, corroborating the score averages and signaling the urgency of these learning foci. The element averaging highest, Detecting my own mistakes, coincides with today's pedagogic trend towards reflective practice [41], encouraging the implementation of strategies that help students to help themselves.

The importance of Academic style, ranking second in the present survey, is confirmed by also other studies showing that the author's specific stylistic and organizational choices matter greatly as they support overall text usability but also the buildup of author credibility and content reliability by steering reader perceptions [42]. Style is probably the most evident feature of academic writing: it materializes in many aspects and levels of writing and visibly manifests the register or genre of the text. Fortunately, as style mostly materializes in micro-level language usage, it is also easy and quick to improve. However, the composition of text not only involves micro-level 
mechanics of writing but also deeper, macro-level strategies supporting argumentation and positioning and enhancing persuasion and credibility aims [43].

Both the quantitative and qualitative studies revealed handicaps in author ability to make solid arguments instead of conveying insights or intuitive opinions. In the present survey, student concerns over preciseness convey an academic awareness and stance, as precision and accuracy constitute important features of academic writing, especially in terms of argumentation. Precision and clarity of expression are particularly essential when critically reporting one's own empirical results but also when objectively reviewing other authors' studies while providing sufficient credit [44], [45].

Alarmingly, the top-5 list includes a mental component, Getting started with writing, which draws attention to the socio-emotive load involved in the writing process. Students' writing strategies obviously require more attention but due to time constraints in a course as short as 36 hours, and also due to teacher unpreparedness for such a demanding topic, the writer's block is addressed only superficially in small group discussions and teacher feedback sessions and some general guidelines are sketched for drafting a new text. However, the teacher is adamant about future inclusion of such mental processes.

Grammar being raised as a challenge was somewhat surprising, as the English proficiency level is extremely high among doctoral candidates. This result can perhaps be explained by the European education system, in which language teaching has traditionally placed much emphasis on grammar and correctness. As a result, students are proficient but also excessively cautious about making mistakes. Correct grammar is naturally a concern in academic writing that aims at publication but respondent biases stemming from educational emphases may have influenced the scores received for this question item. Also social desirability and the pressure students sense from the environment may encourage them to emphasize grammar in a survey that was organized by a Language Centre. The author is therefore inclined to attribute some of this concern rather to the education culture than any severe handicaps in the area.

An analysis of the received data for score averages, medians and standard deviations yielded a priority of course topics, with the averages indicated in Figure 2.

Due to the small sample size $(n=381)$ and rather unscientific labeling of the question items based on the preliminary student responses, these results have to be regarded as suggestive. However, they provide indication of the average needs of the majority and thereby suggest emphases for the course design. 


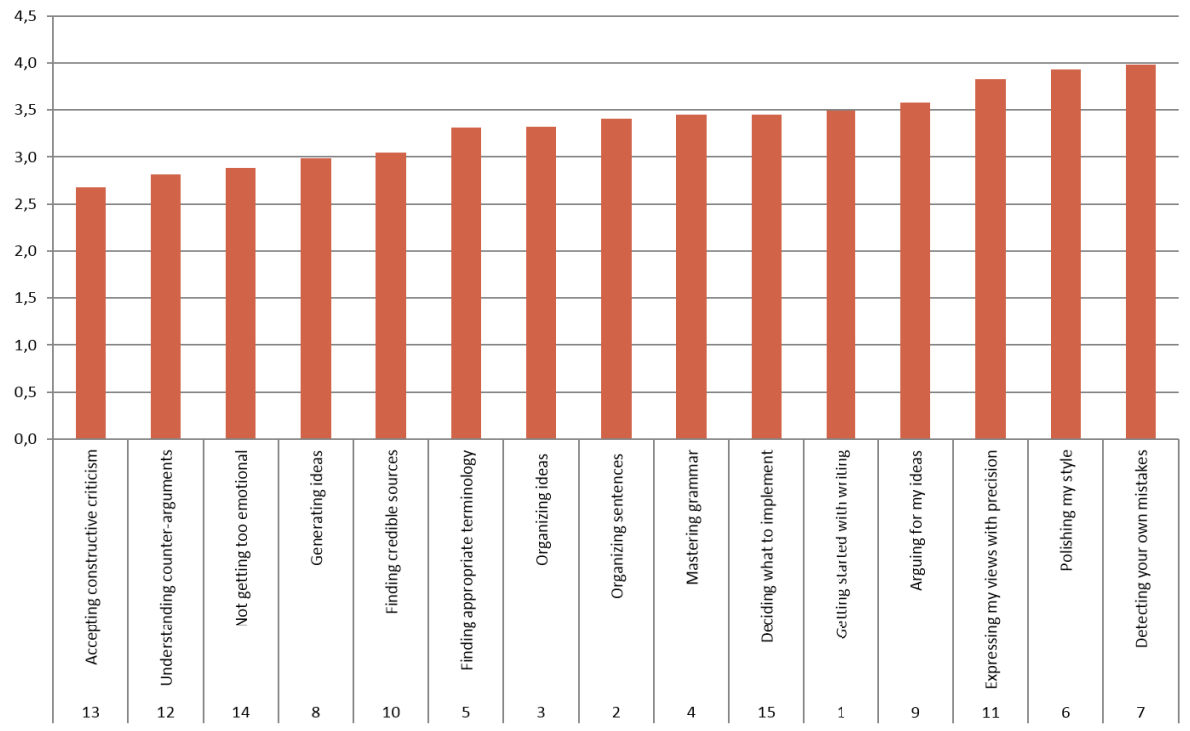

Fig. 2. Thematic priorities based on the quantitative survey.

\subsection{Subsequent course principles}

Based on the data analyzed for the purposes of the present doctoral course design, the development endeavor described in this article deviated from bachelor's and master's-level foci on language proficiency in other language courses at the University. To build on the knowledge acquired during basic degree studies and to elevate the level of difficulty of the learning content, this course centers on communicative aspects. The key pedagogic principle, usability, was adopted from the international ISO standard, which defines usability as "The extent to which a product can be used by specified users to achieve specified goals with effectiveness, efficiency, and satisfaction in a specified context of use" [46]. This aligns effectively with the aims of a course that promotes successful journal review outcomes, with publications being the products.

Effectiveness in the related course refers to message accuracy and unambiguousness, methodological validity, data reliability and scientific data commentary conventions that provide due credit to original authors and leave the tone unaltered from the initial reporting. Efficiency was translated to this context as conciseness and lack of redundancy. Typically it also involves avoidance of nominalization and phrasal verbs, and a shift in voice from passive to active, which harnesses subject-verb connection and subsequent text intelligibility and flow, reducing reader effort. Finally, user satisfaction here means readability and the subjective user experience, which can be promoted through appropriate terminology, academic style, coherence and logical topicalization.

In addition to a strong focus on usability topics, the course was founded on two pedagogic principles. First, all materials and exercises were authentic engineering 
samples in a language bath style, to accustom the students to engineering conventions, jargon and idioms in a fashion as holistic and effective as possible. Second, the course put effort to ridding students of writing inhibitions by repeatedly highlighting two guidelines: 1) one learns to write by writing, and 2) quality comes from revision. These guidelines were enforced through continuous, constructive feedback, which departed from acknowledgement that the first draft is by default incomplete but will eventually grow into full-fledged academic output through iterative revising and peer input.

\subsection{Course design}

The 3 ECTS Writing Doctoral Research course follows the standard 36-hour frame of the University, with 9 sessions organized into 4-hour blocks (Figure 3). The sessions were organized and built on the foundation of the survey results as follows:

1. As the survey indicated already with smaller samples, detecting one's own mistakes $\left(1^{\text {st }}\right)$ poses challenges to any writer, which is why a peer review was added early on to the end of every session. By monitoring mistakes in a peer's paper, researchers learn to detect errors in their own manuscripts. In addition, 4 of the sessions were dedicated entirely to teacher/peer feedback for more detailed scrutiny.

2. As style emerged as the most critical topic $\left(2^{\text {nd }}\right)$, an entire session was dedicated to stylistic features in academic writing for publication.

3. Precision of claims and accuracy of arguments ranked $3^{\text {rd }}$ and $6^{\text {th }}$, respectively, indicating that reporting posed problems for the doctoral candidates in the sample. A session was therefore designed to cover data commentary and reporting conventions, which provide most incidents and a logical ground for claim statements and arguments.

4. Organization of sentences and ideas were identified as difficult $\left(7^{\text {th }}\right.$ and $9^{\text {th }}$, respectively), which revealed the need to focus on coherence, redundancy, readability and flow, that is, aspects impacting reader satisfaction.

5. Grammar $\left(4^{\text {th }}\right)$ was subtly integrated to all sessions and teacher reviews as an inherent component in a language course.

6. Such mental issues as writing inhibitions $\left(5^{\text {th }}\right)$ as well as processes involved in feedback (emotionality $14^{\text {th }}$ and acceptance of criticism $15^{\text {th }}$ ) were focused on in the last, wrap-up sessions in a targeted fashion but naturally also whenever emotional challenges were addressed by students in class.

7. Additionally, the qualitative analysis revealed that engineers lacked patterns and strategies establishing the relevance of their topic, as well as rhetorical elements supporting their positioning. These themes comprised the course opening and allowed the doctoral candidates to delve into their Introductions and Abstracts.

Overall, the course skeleton could be depicted as illustrated in Figure 3. 


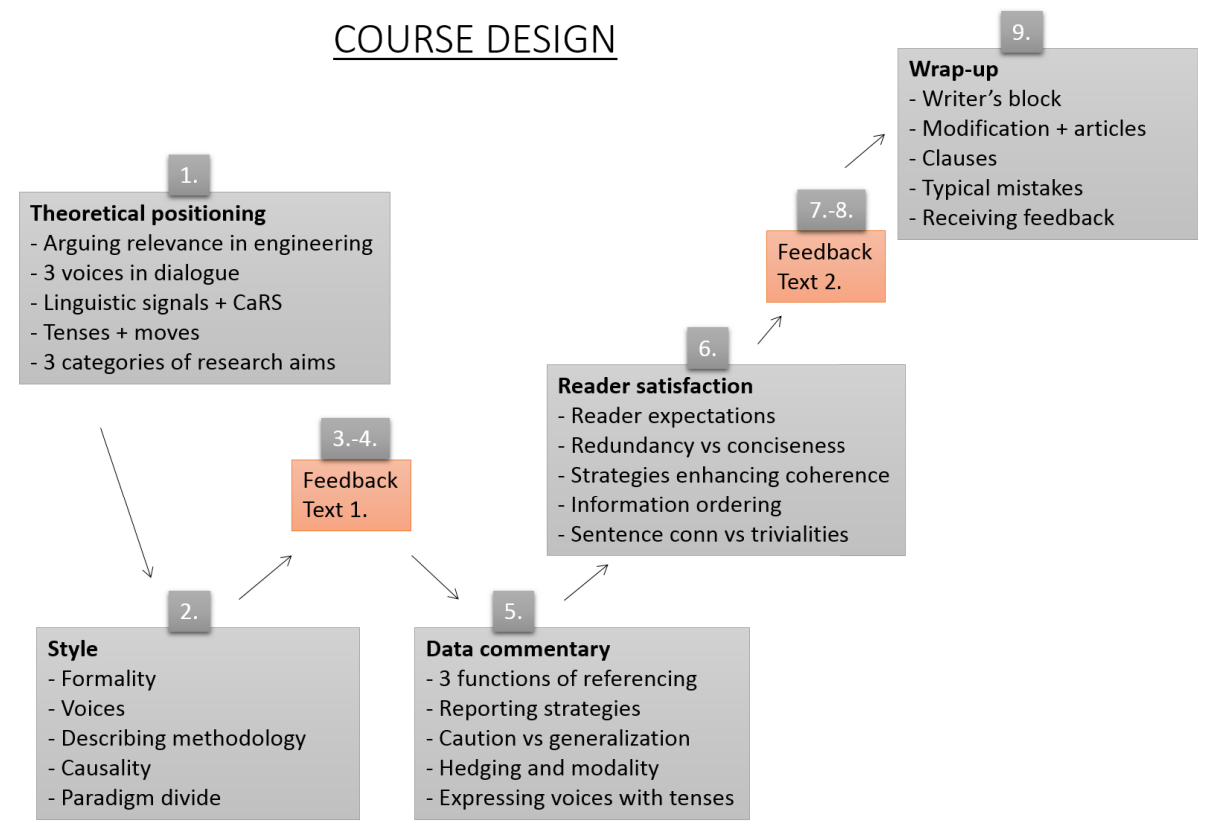

Fig. 3. Writing Doctoral Research course organization.

Four of the sessions are dedicated to half-group teacher/peer-reviews so that each candidate receives feedback that is prepared beforehand on his/her manuscript twice during the course. In addition, each lecture ends in a 30-minute peer review, in which students monitor each other's products against a checklist that reviews the topics covered in the session in question. This serves as means of responding to student calls for more mentoring, mental support and face-to-face supervision. It is also a solution to the number 1 problem raised in the analysis: detecting mistakes in their own writing.

It is important to note that even after 6 years, the course is still work in progress. In alignment with the principles of design-based research, the course evolves continually through iteration based on new student groups' needs and feedback. Continuous development is naturally a necessity also as the doctoral candidates' manuscripts focus on technology topics; to secure authenticity, relevance and up-datedness, the examples and exercises must keep up with real-life trends and technological development.

\section{$4 \quad$ New policy call}

University units typically demonstrate their qualification through research orientation, with staff excellence being measured by publication productivity. Fortunately, the shift in focus towards didactic and pedagogical competences [47] is directing attention to teachership that positively impacts learning outcomes. Such verbal and 
nonverbal behaviors that lead to student empowerment, motivation and perception of connectedness stem from teacher's service-mindedness and positively alter the student-teacher relationship [48], supporting post-graduate study progress and expediting degree completion [49].

A fundamental change of this magnitude in teaching practices is urged by calls to move from processual transmission of substantive knowledge to a more holistic buildup of professional expertise and reflective practice in engineering education [50]. Teachers are expected not only to master their subject matter but also to know their learners and learner needs [51]. This is fundamental when designing targeted curricula for the doctoral level [52].

Securing teachers' professional development serves as a key strategy in educational reform [53]. Improvement towards pedagogic excellence requires distributed leadership, redistribution of power to teachers and continuous learning. In the absence of training and formal education, teachers need to take responsibility for their selfdevelopment but this poses expectations for teacher authority and autonomy, not only as teachers but also as researchers. Pedagogical leadership and the related capacity build-up necessitates democracy and independence, but also initiative, energy, commitment and responsibility - not to mention funding in terms of hours allocated to research [54].

This investigation aims to advance doctoral candidates' benefits by shifting educational reform foci to teacher-researchers, even and especially in the case of language teachers. This has persistently been challenged by policy-level decisions that as language studies represent the non-core, they do not have to be based on empirical research. These arguments overlook the potential in integrated teaching, which intensifies multidisciplinary learning [55].

However, several arguments promote such a reform. First of all, students have the right to expect research-based teaching in all sectors of their degree studies. Second, teacher motivation can easily be elevated by securing the relevance of the education supply through authentic student demands. Third, teachers' competences grow when they are allowed to research and learn more about topics of relevance and of authenticity. Finally, teacher resources can best be secured through research evidence that substantiates the (re-)allocation of scarce university resources in the classroom. However, such institutional and teacher renewal requires efforts from teacher-researchers [56] that must be compensated for.

\section{Conclusion}

The increasingly competitive research economy has pushed universities to reexamine their doctoral offerings. Efforts abound but they have often been accused of being divorced from the problems of everyday practice. To bridge the gap between theoretically oriented institutional policies and classroom practice, this study set out conceptualize an intervention that would draw on authentic post-graduate needs. To design syllabi for the doctoral level that would fill both individual researchers' requirements and those of their host university, this study examined needs and factors 
impacting publication productivity. Scholarly writing was earlier dismissed as a mere cosmetic component of little importance in the overall thesis process, compared to the scientific and empirical investigation. It has also been regarded as a skill that could be taught separate from content and context [57]. This, however, underestimates the complexity of thesis writing, in which the field-specific conventions, unique discourses and research traditions dictate and characterize the writing style and structure.

A particular challenge with doctoral education stems from the pressure to address both the quality and the quantity of doctoral outputs. Students often regard these as competing aims, but contrastively, this study implies that investment in one, quality, bolsters the other, quantity, as facilitation of academic writing strategies tends both to lift the quality of writing and to speed up the writing process. Overall, the analysis reported in this article not only points out emphases for a doctoral writing course but also signals that thesis completion depends strongly on university-provided support for the writing process, directed to such dimensions of text usability as efficiency, effect and reader satisfaction, as well as the authors' mental processes.

When aligning with the recent trends for demand-driven education and service orientation, the performability of research support can no longer be measured only in terms of such calculable terms as publication productivity and degree attainment time. Instead, or rather additionally, focus ought to be directed to quality: the motivational aspects embedded in the supervision process, including inspiration and emotive support as well as the level of specificity and contextualization of teaching content deserve more attention.

Such a new stance to investment in and monitoring of research outputs requires capacity building, not only of teachership but also of the entire university arena. This is the only way towards a broader scope of education, a more productive researcher base - and a more sustained transformation of the university institution into a highperforming service unit. However, it is important to acknowledge that ultimately the transformation takes place in the classroom and is led by teacher-researchers, for whom analysis of student needs should be made business as usual among their constant efforts to improve educational practices.

\section{References}

[1] G. Bossa, "Europe's Universities in Response to Europe's Challenges". Higher Education in Europe, 2006, Vol. 31(4), pp. 355-357. https://doi.org/10.1080/03797720701302907

[2] A. Harris, "Leading system-wide improvement". International Journal of Leadership in Education: Theory and Practice, 2012, Vol. 15(3), pp. 395-401. https://doi.org/10.1080/13603124.2012.661879

[3] S. Nawaz and J. Strobel, J. "Authorship and Content Analysis of Engineering Education Research. A Case Study". International Journal of Engineering Pedagogy, 2016, Vol. 6(2), pp. 39-51. https://doi.org/10.3991/ijep.v6i2.5577

[4] B.Williams, P. Neto, and P. Wankat, "Taking a Snapshot: Four Bibliometric Indicators To Track Engineering Education Research Evolution”. International Journal of Engineering Pedagogy, 2014, Vol. 4(4), pp. 16-22. https://doi.org/10.3991/ijep.v4i4.3843 
Paper-Teacher-Researchers as Levers of Doctoral Curriculum in Engineering

[5] K. Bauer and N. Bakkalbasi, "An Examination of Citation Counts in a New Scholarly Communication Environment”. D-Lib Magazine, 2005, Vol. 9(11), http://www.dlib.org/dlib/september05/bauer/09bauer.html. https://doi.org/10.1045/septem ber2005-bauer

[6] C. Halse and J. Malfroy, "Retheorizing doctoral supervision as professional work". Studies in Higher Education, 2010, Vol. 35(1), pp. 79-92. https://doi.org/10.1080/0307 5070902906798

[7] C. Aitchison and A. Lee, "Research writing: problems and pedagogies". Teaching in Higher Education, 2006, Vol. 11(3), pp. 265-278. https://doi.org/10.1080/13562510 600680574

[8] A. Harris, "Leading system-wide improvement". International Journal of Leadership in Education: Theory and Practice, 2012, Vol. 15(3), pp. 395-401. https://doi.org/10.1080/13 603124.2012.661879

[9] L. McAlpine and C. Amundsen, "Challenging the taken-for-granted: how research analysis might inform pedagogical practices and institutional policies related to doctoral education”. Studies in Higher Education, 2012, Vol. 37(6), pp. 683-694. https://doi.org/10.1080/ 03075079.2010 .537747

[10] C. Bruce and I. Stoodley, "Experiencing higher degree research supervision as teaching". Studies in Higher Education, 2013, Vol. 38(2), pp. 226-241. https://doi.org/10.1080/ 03075079.2011 .576338

[11] J. Cumming, "Doctoral enterprise: a holistic conception of evolving practices and arrangements". Studies in Higher Education, 2010, Vol. 35(1), pp. 25-39. https://doi.org/10.1080/03075070902825899

[12] M. Ehses and M. Veith, "The International Research Training Group (GRK532): Practicing Cross-border Postgraduate Education". Higher Education in Europe, 2009, Vol. 3-4, pp. 367-384. https://doi.org/10.1080/03797720903355620

[13] U. Oberst, et al. "Training Emotional and Social Competences in Higher Education", Higher Education in Europe, 2009, Vol. 34(3-4), pp. 523-533. https://doi.org/10.1080/ 03797720903392243

[14] C. Halse and J. Malfroy, "Retheorizing doctoral supervision as professional work". Studies in Higher Education, 2010, Vol. 35(1), pp. 79-92. https://doi.org/10.1080/0307 5070902906798

[15] L. Suarez and W. Hernandez, "Leadership and performance in higher education: a comparative analysis in Portugal and Spain". European Journal of Engineering Education, 2012, Vol. 37(6), pp. 592-599. https://doi.org/10.1080/03043797.2012.729810

[16] B. Crossouard, "Conceptualising doctoral researcher training through Bernstein's theoretical frameworks". International Journal for Researcher Development, 2013, Vol. 4(2), 7285. https://doi.org/10.1108/IJRD-05-2013-0007

[17] T. Saarinen and T. Ala-Vähälä. "Accreditation, the Bologna Process and National Reactions: Accreditation as Concept and Action". Higher Education in Europe, 2007, 32(4), 333-345. https://doi.org/10.1080/03797720802066195

[18] C. Halse and J. Malfroy, "Retheorizing doctoral supervision as professional work". Studies in Higher Education, 2010, Vol. 35(1), pp. 79-92. https://doi.org/10.1080/03075 070902906798

[19] A. Franke and B. Arvidsson, "Research supervisors' different ways of experiencing supervision of doctoral students. Studies in Higher Education, 2011, Vol. 36(1), pp. 7-19. https://doi.org/10.1080/03075070903402151

[20] L. McAlpine, C. Amundsen, "Challenging the taken-for-granted: how research analysis might inform pedagogical practices and institutional policies related to doctoral educa- 
Paper-Teacher-Researchers as Levers of Doctoral Curriculum in Engineering

tion”. Studies in Higher Education, 2012, Vol. 37(6), pp. 683-694. https://doi.org/10.1080/ 03075079.2010 .537747

[21] A. Harris, "Leading system-wide improvement". International Journal of Leadership in Education: Theory and Practice, 2012, Vol. 15(3), pp. 395-401. https://doi.org/10.1080/13 603124.2012 .661879

[22] D. Malouf and J. Taymans, "Anatomy of an Evidence Base". Educational Researcher, 2016, Vol. 45(8), pp. 454-459. https://doi.org/10.3102/0013189X16678417

[23] A. Harris, "Leading system-wide improvement". International Journal of Leadership in Education: Theory and Practice, 2012, Vol. 15(3), pp. 395-401. https://doi.org/10.1080/13 603124.2012.661879

[24] D. Hargreaves, "System redesign for system capacity building". Journal of Educational Administration, 2011, Vol. 49(6), pp. 685-700. https://doi.org/10.1108/09578231111 174820

[25] A. McNeil, D. Prater, D. and S. Buschint, "The effects of school culture and climate on student achievement". International Journal of Leadership in Education, 2009, Vol. 12(1), pp. 73-84. https://doi.org/10.1080/13603120701576241

[26] A. Harris, "Leading system-wide improvement". International Journal of Leadership in Education: Theory and Practice, 2012, Vol. 15(3), pp. 395-401. https://doi.org/10.1080/13603124.2012.661879

[27] D. Hargreaves, "System redesign for system capacity building". Journal of Educational Administration, 2011, Vol. 49(6), pp. 685-700. https://doi.org/10.1108/09578231111 174820

[28] C. Bruce and I. Stoodley, "Experiencing higher degree research supervision as teaching". Studies in Higher Education, 2013, Vol. 38(2), pp. 226-241. https://doi.org/10.1080/0307 5079.2011.576338

[29] M. Martinsuo and V. Turkulainen, "Personal commitment, support and progress in doctoral studies". Studies in Higher Education, 2011, 36(1), pp. 103-120. https://doi.org/10.1080/ 03075070903469598

[30] T. Woodall, A. Hiller and R. Sheilagh, "Making sense of higher education: students as consumers and the value of the university experience". Studies in Higher Education, 2014, Vol. 39(1), pp. 48-67. https://doi.org/10.1080/03075079.2011.648373

[31] A. Harris, "Leading system-wide improvement". International Journal of Leadership in Education: Theory and Practice, 2012, Vol. 15(3), pp. 395-401. https://doi.org/10.1080/ 13603124.2012 .661879

[32] D. Boud and A. Lee, "Peer learning as pedagogic discourse for research education". Studies in Higher Education, 2005, Vol. 30(5), pp. 501-516. https://doi.org/10.1080/030750 70500249138

[33] K. Lahenius and M. Martinsuo, "Personal study planning in doctoral education in industrial engineering". European Journal of Engineering Education, 2010, Vol. 35(6), pp. 607618. https://doi.org/10.1080/03043797.2010.500719

[34] Le, K. and Tam. V. "How to retain postgraduate students in engineering programmes: a practical perspective". European Journal of Engineering Education, 2008, Vol. 33(5-6), pp. 511-524. https://doi.org/10.1080/03043790802564087

[35] A. Kolmos, L.B. Kofoed and X.Y. Du, "PhD students' work conditions and study environment in university- and industry-based $\mathrm{PhD}$ programmes". European Journal of Engineering Education, 2008, Vol. 33(5-6), pp. 539-550. https://doi.org/10.1080/0304379 $\underline{0802588383}$

[36] R. Kling and G. McKim, "Scholarly communication and the continuum of electronic publishing". Journal of the American Society for Information Science, 1999, Vol. 50(10), pp. 
Paper-Teacher-Researchers as Levers of Doctoral Curriculum in Engineering

890-906. https://doi.org/10.1002/(SICI)1097-4571(1999)50:10<890::AID-ASI6>3.0.CO;2$\underline{8}$

[37] U-M. Bergroth-Koskinen and R. Seppälä, "Teacher-researchers Exploring Design-based Research to Develop Learning Designs in Higher Education Language Teaching". Apples - Journal of Applied Language Studies, 2012, Vol. 6(2), pp. 95-112.

[38] Design-Based Research Collective. "Design-based research: An emerging paradigm for educational inquiry". Educational Researcher, 2003, Vol. 32(1), pp. 5-8. https://doi.org/10.3102/0013189X032001005

[39] R. Murray, How to Write a Thesis. Open University Press, McGraw-Hill Education, 2009.

[40] A. Lee and B. Kamler, "Bringing pedagogy to doctoral publishing". Teaching in Higher Education, 2008, Vol. 13(5), pp. 511-523. https://doi.org/10.1080/13562510802334723

[41] H. Hickson, "Critical reflection: reflecting on learning to be reflective". Reflective Practice: International and Multidisciplinary Perspectives, 2011, Vol. 12(6), pp. 829-839. https://doi.org/10.1080/14623943.2011.616687

[42] C. Hilton, W. Motes, and J. Fielden, , "An Experimental Study of the Effects of Style and Organization on Reader Perceptions of Text". Journal of Business Communication, 1989, Vol. 26(3), pp. 255-270. https://doi.org/10.1177/002194368902600304

[43] D. Hacker, “A Writer's Reference”. Bedford/St. Martin,'s, Boston, the USA, 1999.

[44] H. Uusitalo, H, "Tiede, tutkimus ja tutkielma" (Translated by P.L.: Science, research and thesis). WSOY, 1997.

[45] K. Hakkarainen, K. Lonka, K. and L. Lipponen, L., Tutkiva oppiminen (Translated by P.L.: Explorative learning), WSOY, 1999.

[46] International Organization for Standardization. http://www.iso.org/iso/home.html (acquired 28.12.2016)

[47] G. Kurz, "Promotion of Pedagogical Abilities of Engineering Lecturers". Published in TREE - Teaching and Research in Engineering in Europe (Eds. C. Borri, \& F. Maffioli, F.), 2007, Erasmus Thematic Network. Firenze University Press.

[48] P. King and P. Witt, "Teacher Immediacy, Confidence Testing, and the Measurement of Cognitive Learning". Communication Education, 2009, Vol. 58(1), pp. 110-123. https://doi.org/10.1080/03634520802511233

[49] A. Franke and B. Arvidsson, "Research supervisors' different ways of experiencing supervision of doctoral students". Studies in Higher Education, 2011, Vol. 36(1), pp. 7-19. https://doi.org/10.1080/03075070903402151

[50] P. Lappalainen, Socially Competent Leadership - predictors, impacts and predictors in engineering, 2012, Lappeenranta University of Technology, Dissertation Series.

[51] L. Darling-Hammond, "The quiet revolution: rethinking teacher development". Educational Leadership, 1996, Vol. 53(6), pp. 4-10.

[52] K. Lahenius and M. Martinsuo, "Personal study planning in doctoral education in industrial engineering". European Journal of Engineering Education, 2010, Vol. 35(6), pp. 607618. https://doi.org/10.1080/03043797.2010.500719

[53] L. Darling-Hammond, "The quiet revolution: rethinking teacher development". Educational Leadership, 1996, Vol. 53(6), pp. 4-10.

[54] L. Lambert, "Lasting leadership: towards sustainable school improvement". Journal of Educational Change, 2007, Vol. 8(4), pp. 311-23. https://doi.org/10.1007/s10833-007$\underline{9046-6}$

[55] P. Lappalainen, "Integrated Language Education - A Means of Enhancing Engineers' Social Competences". European Journal of Engineering Education, 2010, Vol. 35(4), pp. 393-403. https://doi.org/10.1080/03043797.2010.488290 
[56] U-M. Bergroth-Koskinen and R. Seppälä, "Teacher-researchers Exploring Design-based Research to Develop Learning Designs in Higher Education Language Teaching". Apples - Journal of Applied Language Studies, 2012, Vol. 6(2), pp. 95-112.

[57] B. Paltridge et al., "Doctoral writing in the visual and performing arts: two ends of a continuum. Studies in Higher Education, 2012, Vol. 37(8), pp. 989-1003. https://doi.org/10.1080/03075079.2011.562285

\section{$7 \quad$ Author}

Pia Lappalainen (pia.lappalainen@aalto.fi) is a Doctor of Science in Technology, an English Major, and a Communications Minor. She currently works as Visiting Professor in Leipzig University in Germany and as Lecturer at Aalto University and Helsinki University in Finland. She is an Organizations and Management researcher with an interest in academic writing. Her mission is to develop doctoral curricula into evidence-based programs that promote researcher motivation and performance.

Article submitted 12 February 2017. Published as resubmitted by the author 17 March 2017. 